Yavuz Hakan Ozdemir

Taner Cosgun

Ali Dogrul

Baris Barlas

http://dx.doi.org/10.21278/brod67204

ISSN 0007-215X

eISSN 1845-5859

\title{
A NUMERICAL APPLICATION TO PREDICT THE RESISTANCE AND WAVE PATTERN OF KRISO CONTAINER SHIP
}

\author{
UDC 629.5(05) 629.544:629.5.015.2:519.6 \\ Professional paper
}

\begin{abstract}
Summary
In this study, the computational results for KRISO Container Ship (KCS) are presented. CFD analyses are performed to simulate free surface flow around KCS by using RANS approach with success. Also the complicated turbulent flow zone behind the ship is well simulated. The RANS equations and the non-linear free surface boundary conditions are discretized by means of a finite volume scheme. The numerical methodology is found to be appropriate for simulating the turbulent flow around a ship in order to estimate ship total resistance and free surface. By the numerical results, total resistance is calculated for the ship model and the result is satisfactory with regard to the experimental one. As a result of well captured free surface, the wave elevation on/around the hull is compared with the experimental results.
\end{abstract}

Key words: $\quad$ computational fluid dynamics (CFD); turbulent free surface flows; wave cut; ship resistance; KCS

\section{Introduction}

The KRISO Container Ship (KCS) was considered to provide data for both explication of flow physics and Computational Fluid Dynamics (CFD) validation for a modern ship with bulbous bow. The large cargo ship intended for transportation of containers developed in the Korea Research Institute for Ships and Ocean Engineering (KRISO). No full-scale ship ever exists. Korea Research Institute for Ships and Ocean Engineering performed towing-tank experiments to obtain resistance and wave field. Ship Research Institute of Japan performed towing-tank experiments to obtain hull surface pressure and velocity fields. Estimation of total ship resistance has been an essential topic in ship hydrodynamics. Successful design and optimization of marine structures require information about the flow problem on both integral and field quantity levels. In order to estimate both total resistance and flow properties around a ship, many studies have been done.

The methods which are based on potential theory may be insufficient in case of complexity in ship geometry. Also the viscosity phenomenon is neglected in potential theory. 
Yavuz Hakan Ozdemir, Taner Cosgun,

Ali Dogrul, Baris Barlas
A Numerical Application to Predict the Resistance and Wave Pattern of KRISO Container Ship

With the developments in computer technology, scientists have started to study flow around ships with solving Navier-Stokes equations. By the help of computers, it has been able to model the flow around floating bodies by using appropriate turbulence model. Over the last few decades, RANS based numerical approaches are widely used in ship design. Kouh et al. [1] have investigated scale effect on ship form factor for different hull geometries. In this RANS based study, double body analyses are made to observe the variation of ship form factor with Reynolds number. Park et al. [2] have designed an optimum skeg for a ship via RANS approach and different skeg geometries are analyzed numerically without free surface. In the work of Atlar et al. [3], optimum anti-slamming bulbous bow and tunnel stern geometries for a deep V catamaran are determined with RANS based simulations. Free surface flow around various commercial ships is examined by Choi et al. [4] and resistance components, free surface deformation, velocity profile on propeller plane are gained with the help of RANSE based solver and compared with the experimental results. Compared results show that streamlines along the ship hull and flow separations can be accurately estimated with this technique. An optimization effort for ship hull is made by coupling RANS based solver and genetic algorithm for series 60 parent hull by Bettle et al. [5]. Guo et al. [6] have carried out some numerical analyses in order to validate RANS approach by calculating ship resistance and flow field around KVLCC 2 hull with different turbulent models. Numerical simulations have been carried out for estimation of wake field for high speed ships with mesh refinement to model bow wave breaking by Wang et al. [7].

Nowadays, RANSE approaches are applied with success for different ship types such as fully submerged bodies [8] or multi hull ships e.g. catamaran [9] and trimarans [10]. It is possible to say that, accuracy of RANSE approaches on the estimation of resistance components is significantly improved over the last decades [11], on the other hand, there may be some problems to predict the wave profiles on the ship hull [12] and wave deformation in the far field [13].

Many commercial codes have been developed to solve Reynolds-Averaged NavierStokes (RANS) equations. Ahmed et al. [14] made a study using both potential theory and RANS method to estimate total ship resistance. Sridhar et al. [15] investigated friction resistance of a ship with a RANS solver. Kandasamy et al. [16] showed that RANSE solutions are in good agreement with the experimental ones for a high speed catamaran. Pranzitelli et al. [17] investigated the total ship resistance by considering the flow is viscous and steady. Ozdemir et al. [18] made a validation for CFD method with experimental results for a fast ship model.

In order to test the validity and effectiveness of CFD methods based on solving RANS equations, some ship models are offered to be investigated. These models are KRISO Container Ship KCS, US Naval Combatant DTMB 5415 and KRISO Crude Carrier KVLCC2 which have complex hull curvatures. All the models have transom sterns and bulbous bows which make it difficult to solve the flow problem with the methods based on potential theory. Prakash and Subramanian [19] investigated propeller-hull interaction of KCS by coupling Vortex Lattice Method (VLM) and RANSE solver. They have showed that the numerical results are in good agreement with the experimental ones. Chao [20] has investigated propulsion of KCS numerically. Lübke [21] has studied flow around KCS with the propeller. A fresh study has been made by Tezdogan et al. [22] for KCS hull. In this study, full scale CFD analysis KCS has been carried out by considering the ship is free to two degrees of freedom (2DOF). 
In this work, we present computational results for a surface ship, KCS, using viscous free surface calculations. The paper presents a detailed methodology of widely used RANSE based CFD approach. The present study demonstrates that, for the design analysis of a ship hull, computational fluid dynamics techniques can be utilized with a reasonable level of confidence. This method will be described in this paper, together with its application to some ship hull calculation. The focus of the discussion is put on the computational requirements to obtain reliable results. In this approach, far field wave profiles are open to miscalculations. Wave and wake profiles behind the ship are presented in comparison with the experiments. The finite volume solution method is applied to the unsteady turbulent flow simulation around a KCS hull. Viscous effects in the flow are taken into account using the well-known standard k- $\varepsilon$ two equation turbulence model. Unstructured hexahedral grid systems are utilized in the whole fluid domain. The Korea Research Institute for Ships and Ocean Engineering (KRISO) carried out model tests to find resistance, mean flow data and free surface waves for KCS [23]. Through comparing these results with relevant experimental data, it is shown that CFD is a supplement tool to towing tank tests in ship engineering design practice and an invaluable tool to assess the hydrodynamics of the flow around a ship hull. The main focus of this paper is to summarize various results that can be found in the literature and present our own methodology to solve the viscous flow around KCS. The next section of this paper provides brief explanations about the governing equations and detailed explanation of the computational methodology including boundary conditions, computational grid and numerical solution strategy. Then results and discussions are presented.

\section{Geometry and Conditions}

KRISO container ship (KCS) is regularly used as a benchmark for flow computations around ships. The geometry of the KCS model is given in Figure1. The KCS model has a scale of 1/31.6 which is implemented for the numerical calculations. Table 1 gives the model ship and real ship particulars.

Aerodynamic and hydrodynamic forces of KRISO container ship have been investigated by Banks et al. [31]. They showed that aerodynamic force is hundred times smaller than hydrodynamic force. In this study, air velocity is considered as same as the water velocity however the aerodynamic forces are neglected.

While the model experiments were carried out by fixing the model, i.e. fixed from its floating position and it is not free to sinkage and trim, so the numerical model is also considered as fixed which means the ship motions are not permitted. 
Yavuz Hakan Ozdemir, Taner Cosgun,

Ali Dogrul, Baris Barlas
A Numerical Application to Predict the Resistance and Wave Pattern of KRISO Container Ship

Table 1 Geometrical properties of KCS

\begin{tabular}{|c|c|c|c|}
\hline & Symbol & Ship & Model \\
\hline Scale & $\wedge$ & 1 & 31.6 \\
\hline Length between & LPP $(\mathrm{m})$ & 230 & 7.278 \\
\hline Maximum beam of & $\mathrm{B}(\mathrm{m})$ & 32.2 & 1.019 \\
\hline Draft & $\mathrm{T}(\mathrm{m})$ & 10.8 & 0.341 \\
\hline Depth & $\mathrm{D}(\mathrm{m})$ & 19 & 0.601 \\
\hline Block coefficient & $\mathrm{C}_{\mathrm{B}}$ & 0.650 & 0.650 \\
\hline Wetted surface area & $\mathrm{A}_{\mathrm{w}}\left(\mathrm{m}^{2}\right)$ & 9424 & 9.437 \\
\hline Displacement & $\nabla\left(\mathrm{m}^{3}\right)$ & 52030 & 1.648 \\
\hline Froude number & $\mathrm{Fn}$ & 0.26 & 0.26 \\
\hline Velocity & $\mathrm{U}(\mathrm{m} / \mathrm{s})$ & 12.345 & 2.196 \\
\hline
\end{tabular}

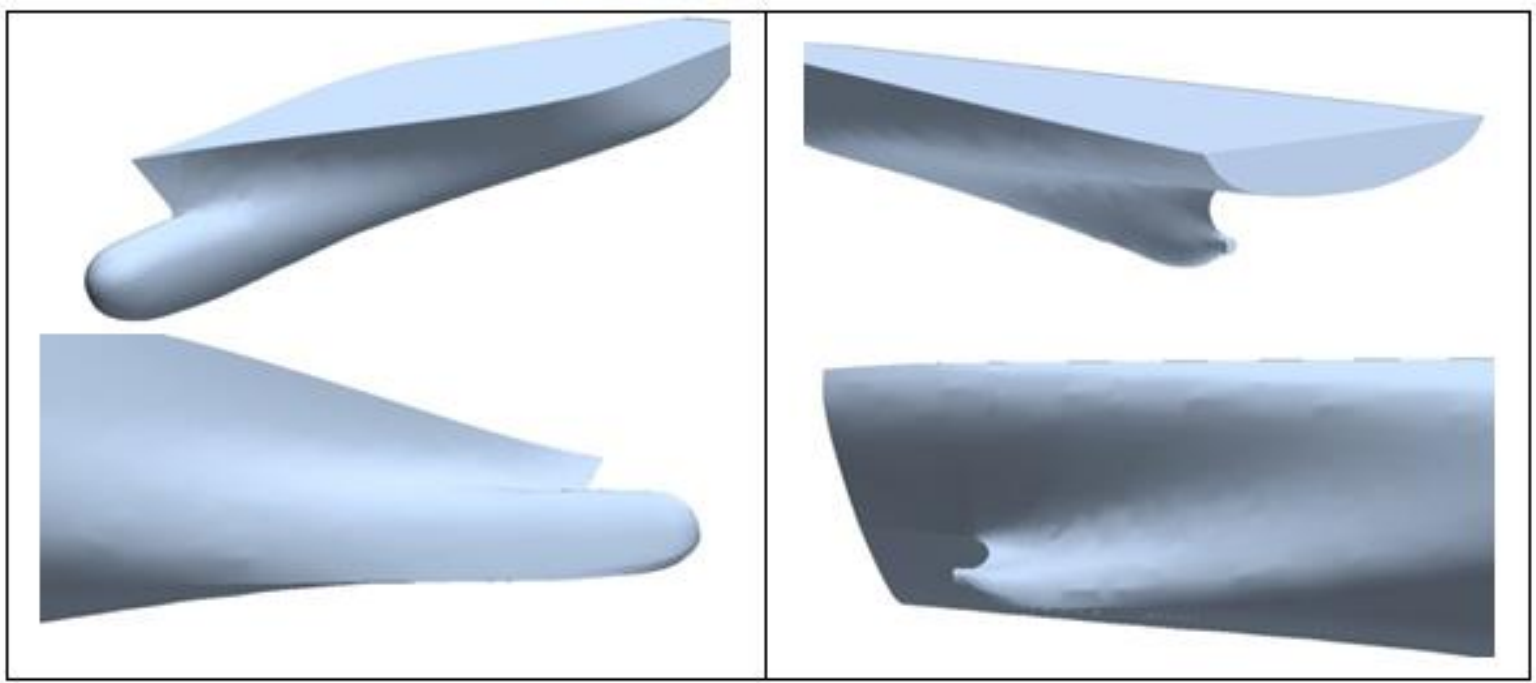

Fig. 1 KRISO container ship (KCS) hull

\section{Mathematical formulation}

The governing equations are the RANS equations and the continuity equation for mean velocity of the unsteady, three-dimensional, incompressible flow. The continuity equation and momentum equations in Cartesian coordinates can be given as;

$$
\frac{\partial U_{i}}{\partial x_{i}}=0
$$


for the continuity and,

$$
\frac{\partial U_{i}}{\partial t}+\frac{\partial\left(U_{i} U_{j}\right)}{\partial x_{j}}=-\frac{1}{\rho} \frac{\partial P}{\partial x_{i}}+\frac{\partial}{\partial x_{j}}\left[v\left(\frac{\partial U_{i}}{\partial x_{j}}+\frac{\partial U_{j}}{\partial x_{i}}\right)\right]-\frac{\partial \overline{u_{i}^{\prime} u_{j}^{\prime}}}{\partial x_{j}}
$$

for the momentum equations.

Where $U_{i}$ and $u_{i}^{\prime}$ express the mean and fluctuation velocity components in the direction of the Cartesian coordinate $\mathrm{x}_{\mathrm{i}}, \mathrm{P}$ the mean pressure, $\rho$ the density and $v$ the kinematic viscosity.

The well-known k- $\boldsymbol{\varepsilon}$ model has been used to simulate the turbulent flows. The Reynolds stress tensor is then calculated by the Boussinesq model;

$$
\overline{u_{i}^{\prime} u_{j}^{\prime}}=-v_{t}\left(\frac{\partial U_{i}}{\partial x_{j}}+\frac{\partial U_{j}}{\partial x_{i}}\right)+\frac{2}{3} \delta_{i j} k
$$

The eddy viscosity $v_{t}$ is expressed as $v_{t}=\mathrm{C}_{\mu} \mathrm{k}^{2} / \varepsilon$, where $\mathrm{C}_{\mu}$ is an empirical constant ( $\mathrm{C}_{\mu}=0.09$ ), $\mathrm{k}$ the turbulent kinetic energy and $\varepsilon$ the dissipation rate of $\mathrm{k}$. The turbulence quantities $\mathrm{k}$ and $\varepsilon$ are then computed from a $\mathrm{k}-\varepsilon$ model using two transport equations,

The turbulent kinetic energy, k, and the rate of dissipation of the turbulent energy, $\varepsilon$, are:

$$
\begin{aligned}
& \frac{\partial k}{\partial t}+\frac{\partial\left(k U_{j}\right)}{\partial x_{j}}=\frac{\partial}{\partial x_{j}}\left[\left(v+\frac{v_{t}}{\sigma_{k}}\right) \frac{\partial k}{\partial x_{j}}\right]+P_{k}-\varepsilon \\
& \frac{\partial \varepsilon}{\partial t}+\frac{\partial\left(k U_{j}\right)}{\partial x_{j}}=\frac{\partial}{\partial x_{j}}\left[\left(v+\frac{v_{t}}{\sigma_{\varepsilon}}\right) \frac{\partial \varepsilon}{\partial x_{j}}\right]+\mathrm{c}_{\varepsilon 1} \mathrm{P}_{k} \frac{\varepsilon}{k}-\mathrm{c}_{\varepsilon 2} \frac{\varepsilon^{2}}{k} \\
& \mathrm{P}_{k}=-\overline{u_{i}^{\prime} u_{j}^{\prime}} \frac{\partial u_{i}}{\partial x_{j}}
\end{aligned}
$$

where, $\mathrm{C}_{\varepsilon 1}=1.44, \mathrm{C}_{\varepsilon 2}=1.92, \mathrm{C}_{\mu}=0.09$, turbulent Prandtl numbers for $\mathrm{k}$ and $\varepsilon$ are $\sigma_{k}=1.0$, and $\sigma_{\varepsilon}=1.3$ respectively.

The use of standard k- $\varepsilon$ two equation turbulence model formulation is reasonably robust, reliable near solid boundaries and recirculation regions like ship boundary layers. The pressure field is solved by using the well-known SIMPLE algorithm [24].

\section{Numerical methods}

\subsection{Boundary conditions}

The volume of control was selected to be of box shape. The height of the computational domain is 2.0 LPP and its width is taken to be of 1.5 LPP due to the symmetry of the problem. The domain inlet boundary is at a distance of 2.0 LPP ahead of the ship, while the outlet boundary is located at 3.0 LPP from the ship stern. The dimensions of the computational domain satisfies ITTC procedure which recommends that inlet boundary should be 1-2 LPP and outlet boundary should be 3-5 LPP away from hull in order to avoid wave reflections [25]. Detailed information 
Yavuz Hakan Ozdemir, Taner Cosgun,

Ali Dogrul, Baris Barlas
A Numerical Application to Predict the Resistance and Wave Pattern of KRISO Container Ship

about the principles of computational domain dimensions can be found in reference 22 . The general view of the computational domain with KCS hull and the notations of boundary conditions are depicted in Figure 2.

At the upstream boundary, the uniform flow condition is used. A hydrostatic pressure profile is specified for the outflow. The center plane is modeled as a symmetry plane and the hull surface as a no-slip wall. The top surface, bottom and far-field boundaries are modeled as free slip walls. An initial velocity boundary condition is used at the beginning of the flow domain.

\subsection{Computational grid}

CFD models using fully viscous three dimensional formulations are typically of the finite volume formulation, which need the computational domain to be discretized into a finite number of three dimensional volumes. The solution mesh may be created using either a structured or unstructured approach. The structured approach requires a 1:1 mapping of grid points in the domain. Unstructured mesh thus greatly simplifies mesh generation for complex geometries, and allows higher quality meshes to be created which result in greater numerical accuracy and faster computation times. Seo et al. [13] modeled the free surface flow around KCS using flexible meshing technique with unstructured elements in curved parts of the ships and structured element in the rest in where has a relatively simple geometry. A commercial CFD software was used in this study and it is concluded that flexible mesh structure gives accurate results to predict the resistance components, on the other hand, the wave deformation away from hull was underpredicted. Free surface flow is analyzed by using hexahedral elements via finite volume method in the study of Zhang [26] and grid convergence studies are conducted. It is shown that hexahedral element structure gives good results in estimation of ship resistance components and wave elevation; besides, finer mesh structure is advised in order to predict far field wave profile better.

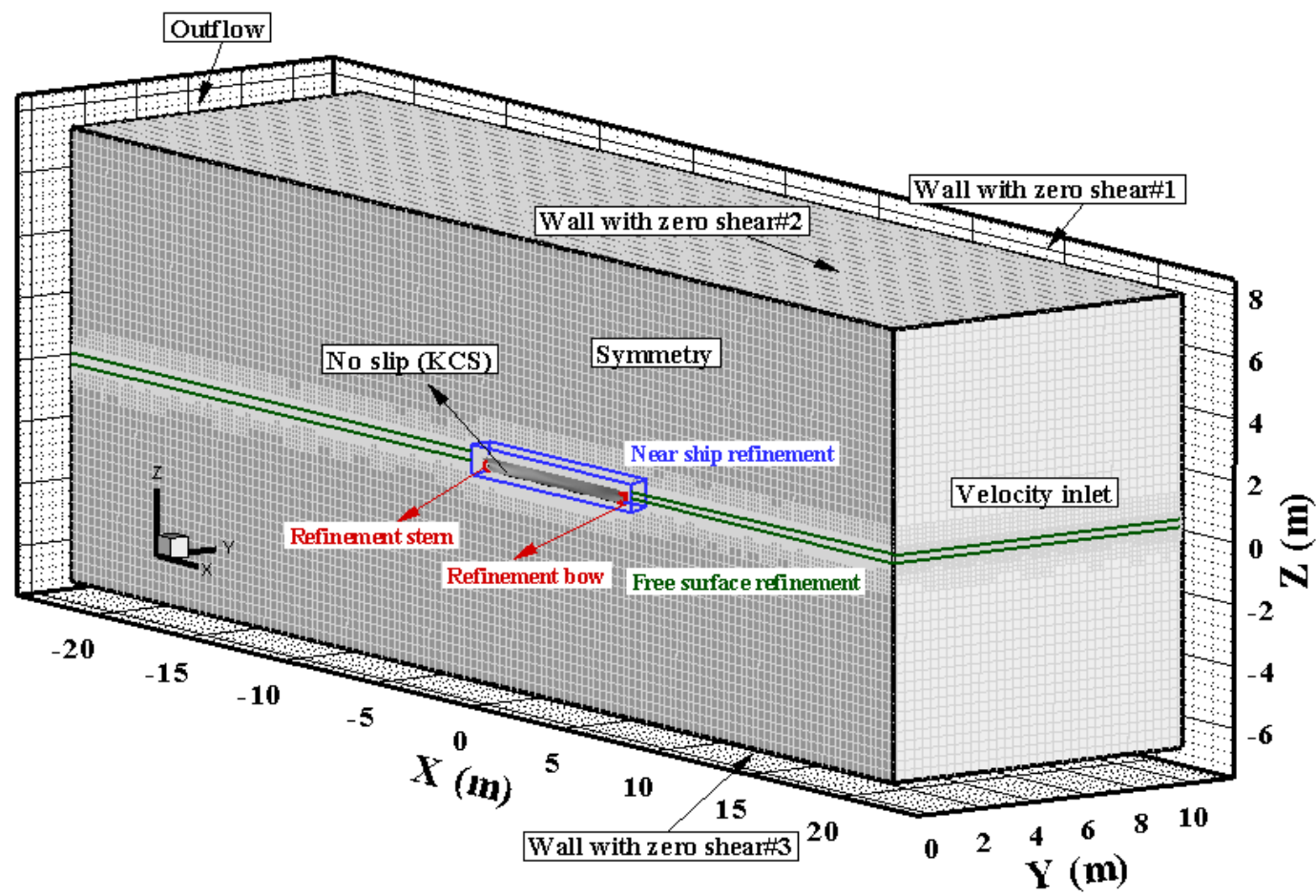


A Numerical Application to Predict the Resistance and Wave Pattern of KRISO Container Ship
Yavuz Hakan Ozdemir, Taner Cosgun

Ali Dogrul, Baris Barlas

Fig. 2 The general view of the domain, boundary conditions and mesh structure (fine mesh)

In this study, an unstructured hexahedral mesh was generated to create the solution domain. A convergence study can be used to extrapolate a mesh independent solution. At least three meshes are essential to estimate the convergence performance. These should be refined in all coordinate directions $\mathrm{i}, \mathrm{j}, \mathrm{k}$ the same refinement factors.

$$
r_{G}^{i, j, k}=\frac{\Delta X_{A}}{\Delta X_{B}}
$$

In our study, three sets of systematically refined grids were generated. A grid development study was implemented using three geometrically similar grids and refinement ratio $\left(r_{G}=\sqrt{2}\right.$ ) was chosen. The unsteady flow around KCS hull is computed at using a coarse $0.4 \mathrm{M}$ grid, $0.8 \mathrm{M}$ grid, and a fine grid of $2.2 \mathrm{M}$ grid system. In all cases, prism layer thickness is fixed in order to keep $y^{+}$values in desired range. The fine mesh structure is shown in Figure 2 and summary of grid sizes and block nomenclature is provided in Table 2. The numerical results and figures have been given for fine mesh structure.

An unstructured hexahedral grid is used to permit for flexibility in grid generation and local mesh refinement for free surface waves. In general, grid points are gathered around the calm water plane in the vertical range of expected wave heights to provide adequate resolution at the free surface interface. It should be noticed that for the viscous flow simulation, the prismatic layer mesh is applied around the hull. Local mesh refinement is achieved by means of volumetric controls of predefined geometrical shapes. The mesh dimensions are determined as a percentage of the ship length. The mesh near the free surface and around the ship hull is refined locally in order to well capture the free surface and solve the complex flow around the hull, while the mesh becomes coarse towards the top and bottom of the volume. For the interphase of the water and air, a block shape is used to refine the free surface zone.

Table 2 Summary of grids for KCS in calm water simulations

\begin{tabular}{|c|c|c|c|}
\hline \multicolumn{4}{|c|}{ Refinement ratio $r_{G}=\sqrt{2}$} \\
\hline & \multicolumn{3}{|c|}{ Grid dimension } \\
\hline Block name & Coarse & Medium & Fine \\
\hline Background & $0.023186 \mathrm{~L}_{\mathrm{PP}}$ & $0.032789 \mathrm{LPP}_{\mathrm{PP}}$ & $0.046372 \mathrm{LPP}_{\mathrm{PP}}$ \\
\hline Near ship refinement & $0.003864 \mathrm{~L}_{\mathrm{PP}}$ & 0.0054305 LPP & 0.007728 LPP \\
\hline Free surface refinement & 0.003864 LPP & 0.0054305 LPP & 0.007728 LPP \\
\hline Refinement bow & $0.000386 \mathrm{~L}_{\mathrm{PP}}$ & 0.000545 LPP & 0.000772 LPP \\
\hline Refinement stern & $0.000386 \mathrm{LPP}_{\mathrm{PP}}$ & $0.000545 \mathrm{~L}_{\mathrm{PP}}$ & $0.000772 \mathrm{~L}_{\mathrm{PP}}$ \\
\hline Prism layer thickness & $0.003091 \mathrm{~L}_{\mathrm{PP}}$ & $0.003091 \mathrm{~L}_{\mathrm{PP}}$ & $0.003091 \mathrm{~L}_{\mathrm{PP}}$ \\
\hline Total number of generated cells & 419892 & 844177 & 2203706 \\
\hline
\end{tabular}


Yavuz Hakan Ozdemir, Taner Cosgun,

Ali Dogrul, Baris Barlas
A Numerical Application to Predict the Resistance and Wave Pattern of KRISO Container Ship

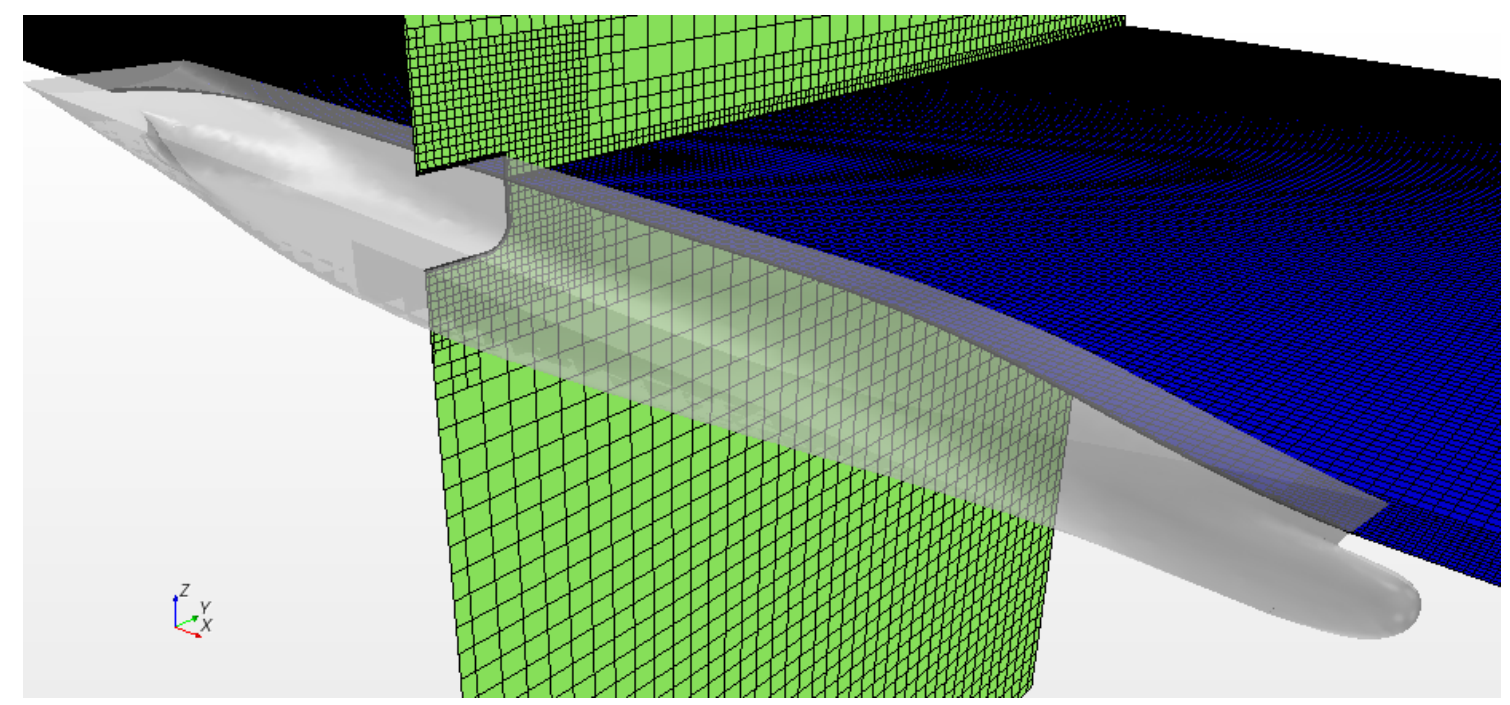

Fig. 3 A cross-section of the computation of unstructured hexahedral mesh

In order to resolve the boundary layer accurately and provide desired levels of wall $y^{+}, 4$ layers of prismatic cells are placed along the hull surface. The stretching factor of prism layers is 1.5 . With such settings of the boundary layer mesh, one achieves the $y^{+}$values in the range from 30 to 120 on the hull. Figure 3 displays a cross-section of the refined unstructured hexahedral mesh to well capture the Kelvin wake. Figure 4 shows the surface mesh on the KCS hull. A refined block was used near the free surface to improve the resolution of the Kelvin wave system.

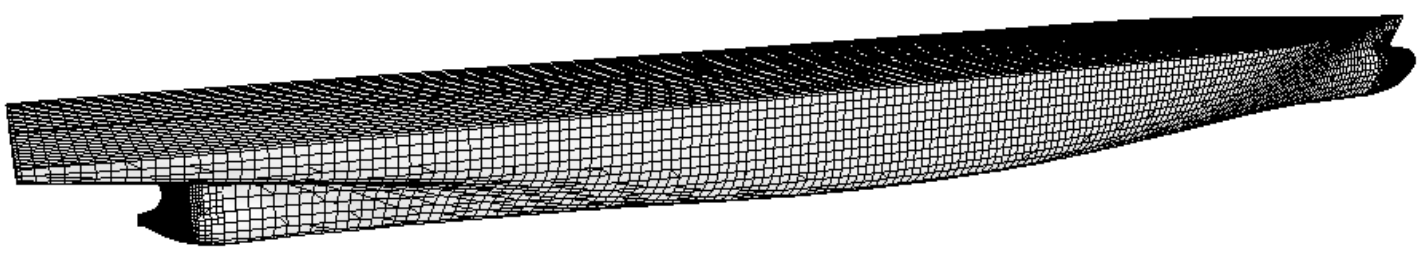

Fig. 4 Surface mesh on hull

\subsection{Solution strategy}

The governing equations described above are discretized using a cell based finite volume method, the advection terms are discretized using a first-order upwind interpolation scheme. The governing equations are solved successively. The pressure field is solved by using the wellknown SIMPLE algorithm [24]. The turbulence quantities are then solved for $\mathrm{k}$ and $\boldsymbol{\varepsilon}$. Since the computations involve certain approximations, an iterative procedure is needed. The solution is considered converged when the normalized residuals of all the variables is lower than $10^{-4}$. Free-surface is modeled using the Volume of Fluid approach (VOF) with a High Resolution Interface Capturing Scheme (HRIC) based on the Compressive Interface Capturing Scheme for Arbitrary Meshes (CISCAM) [27], [28], [29].

Near wall viscous effects are accounted for through the use of wall functions. The boundary layer is modeled using the All- $\mathrm{y}^{+}$wall function option in Star-CCM+. This approach 
gives adequate accuracy for high Reynolds number flows and eliminates the need to fully discretize the boundary layer, which greatly diminishes the overall cell count, which in turn decreases the CPU time required to run the simulation. The wall $y^{+}$on hull is about 30-120. As a RANSE solver, a commercial CFD code (based on finite volume method) Star CCM+6.06 is employed. Detailed descriptions of the numerical method can be found in the User's Guide of this code [30]. Solution settings for the case are summarized in Table 3.

Table 3 Solution settings

\begin{tabular}{|c|c|}
\hline \multicolumn{2}{|c|}{ Solution Settings } \\
\hline Pressure link & SIMPLE \\
\hline Pressure & Standard \\
\hline Turbulence model & $\mathrm{k}-\boldsymbol{\varepsilon}$ \\
\hline Wall function & ${\text { All- }{ }^{+} \text {wall function }}^{|c|}$ \\
\hline Time step & $0.01 \mathrm{~s}$ \\
\hline Iterations per time step & 10 \\
\hline Temporal discretization & 1 st Order \\
\hline
\end{tabular}

\section{Results and Discussions}

The upstream flow velocity is taken as $2.196 \mathrm{~m} / \mathrm{s}$ which give a $F n$ of 0.26 and $R e$ of $1.4 \times 10^{7}$ based on ship length. The time step $\Delta \mathrm{t}$ is chosen to be $0.01 \mathrm{~s}$. ITTC CFD guideline [25] offers a range of 0.005 to $0.01 \mathrm{~L} / \mathrm{U}$ (where $\mathrm{U}$ is the ship velocity and $\mathrm{L}$ is the length between perpendiculars) for time step choice. So, the time step used in the analysis fits in this range. In the following sections, the computational results for the towing case are examined.

\subsection{Resistance}

Conventionally, the result of model resistance test can be expressed as a corresponding relation between resistance coefficient and Froude number in a dimensionless way. The total resistance coefficient is mostly separated into two parts, frictional and residuary resistance coefficient [31]. The coefficient of residuary resistance or pressure resistance $C_{R}$ is equal to difference between total resistance coefficient $C_{T}$ and frictional resistance coefficient $\mathrm{C}_{\mathrm{F}}$. The total resistance in the present study, is expressed in a coefficient form as:

$$
\mathrm{C}_{\mathrm{T}}=\frac{\mathrm{R}_{\mathrm{T}}}{0.5 \rho \mathrm{A}_{w} \mathrm{U}^{2}}
$$

where $A_{W}$ is the static wetted surface area of the model, $U$ is the ship velocity [31]. The grid convergence study for $C_{T}$ is summarized in table 4 , showing comparison of the total resistance coefficients with the experimental data [23]. Table 4 also lists the computer used and the CPU time needed to calculate ship resistance. The numerical results are obtained on a cluster consisting $2.8 \mathrm{GHz}$ and $4 \mathrm{~GB}$ RAM. 
Yavuz Hakan Ozdemir, Taner Cosgun,

Ali Dogrul, Baris Barlas
A Numerical Application to Predict the Resistance and Wave Pattern of KRISO Container Ship

Table 4 Grid convergence study for total resistance coefficient

\begin{tabular}{|c|c|c|c|c|}
\hline & Coarse & Medium & Fine & Experiment \\
\hline $\mathrm{C}_{\mathrm{T}}\left(\times 10^{3}\right)$ & 3.78 & 3.70 & 3.65 & 3.56 \\
\hline Difference $\left|\frac{C F D-E X P}{E X P}\right| \%$ & $6.42 \%$ & $3.94 \%$ & $2.77 \%$ & - \\
\hline $\mathrm{CPU}[\mathrm{h}]$ & 12 & 36 & 48 & - \\
\hline
\end{tabular}

It is seen that as the number of the grid points increased, total resistance is decreased. The fine mesh result is very good with close comparison with experimental result. Grid convergence is estimated using the ratio of the changes in the solution:

$$
R_{G}=\frac{\varepsilon_{21}}{\varepsilon_{32}}=\frac{S_{2}-S_{1}}{S_{3}-S_{2}}
$$

Where $\varepsilon_{21}$ and $\varepsilon_{32}$ give the change of the solutions between the medium-fine and coarse medium girds. The following cases occur:

- Convergence condition: $0<R_{G}<1$

- Oscillatory condition: $R_{G}<0$

- Diverging condition: $R_{G}>1$

From Table 4, we obtain $R_{G}=0.47$, so solution can be considered as converged. The frictional resistance coefficient acting on a body can be calculated by performing an area integral of the wall shear in the x-direction. Frictional resistance coefficient is given:

$$
\mathrm{C}_{F}=\frac{\mathrm{R}_{F}}{0.5 \rho \mathrm{A}_{w} \mathrm{U}^{2}}
$$

The resistance test results are summarized in Table 5, showing comparison of the total resistance coefficients with the experimental data [23]. The total resistance coefficient $\left(C_{T}\right)$ and residuary resistance coefficient $\left(C_{R}\right)$ are compared. Frictional resistance coefficients are computed both using equation 10 and according to ITTC 1957 formula as:

$$
\mathrm{C}_{\mathrm{F}}=\frac{0.075}{\left(\log _{10} \mathrm{Re}-2.0\right)^{2}}
$$

The overall agreement is very good with close comparison with both experimental and ITTC 1957 results. The table also includes results from the Zhang [26] and Seo et al. [13]. The frictional resistance coefficient calculations according to equation 10 are not reported by other authors. Our results is also good agreement other computational total resistance coefficient results. 
Table 5 Comparison of the resistance coefficients.

\begin{tabular}{|c|c|c|c|c|c|}
\hline & Experiment & ITTC 57 & Present study & Zhang & Seo et al. \\
\hline $\mathrm{C}_{\mathrm{T}}\left(\mathrm{x} 10^{3}\right)$ & 3.56 & - & 3.65 & 3.62 & 3.54 \\
\hline $\mathrm{C}_{\mathrm{R}}\left(\mathrm{x} 10^{3}\right)$ & 0.73 & - & 0.78 & - & - \\
\hline $\mathrm{C}_{\mathrm{F}}\left(\mathrm{x} 10^{3}\right)$ & - & 2.83 & 2.87 & Not reported & Not reported \\
\hline
\end{tabular}

Figure 5 illustrates how the resistance coefficients on hull converge towards unsteady solution for fine mesh structure. While frictional resistance very quickly becomes calm to an approximately constant value, residuary force fluctuates around the steady-state value with reducing amplitude.

The simulations are run for a total physical flow time of 150 seconds, at $2.196 \mathrm{~m} / \mathrm{s}$ which corresponds to a distance of $329.4 \mathrm{~m}$ (approximately 45.2 ship lengths). This allows adequate time for the free surface to develop around the vessel, and allows the vessel drag force to converge to a steady value.

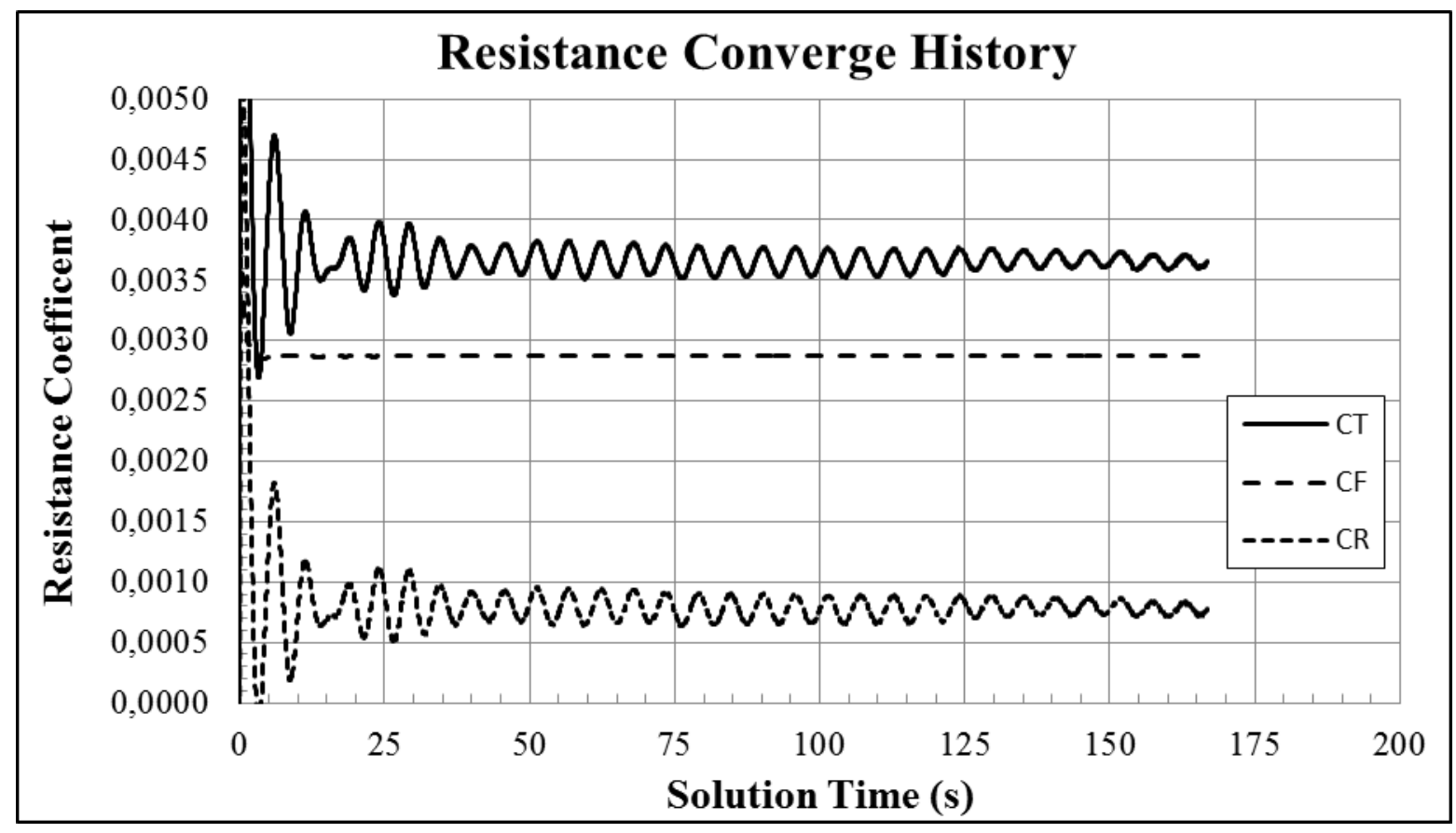

Fig. 5 Convergence of friction, residuary and total drag coefficient during computation

The $y^{+}$variations on the ship model for $F n=0.26$ is given in Figure 6 . The precision of $y^{+}$ values on the hull determines the quality of boundary layer solution which affects the friction force. And it is seen that the $y^{+}$values is ranged between $30<\mathrm{y}^{+}<120$, as required. 
Yavuz Hakan Ozdemir, Taner Cosgun,

Ali Dogrul, Baris Barlas
A Numerical Application to Predict the Resistance and Wave Pattern of KRISO Container Ship

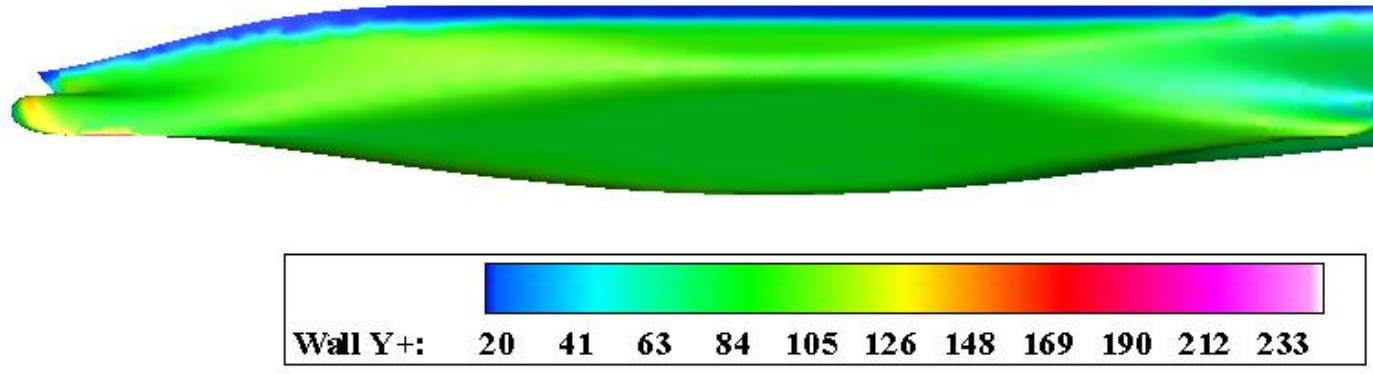

Fig. 6 Computed $\mathrm{y}^{+}$distribution

\subsection{Wave field}

Concerning the calculated results, Figure 7 shows the wave pattern around the ship and again a Kelvin type wave pattern is developed. According to Figure 8, a typical bow wave pattern is observed while Figure 9 shows the stern wave. The wave damping in the outer walls of the computational domain shows that the boundary dimensions are good enough to simulate the free surface around the ship hull form.

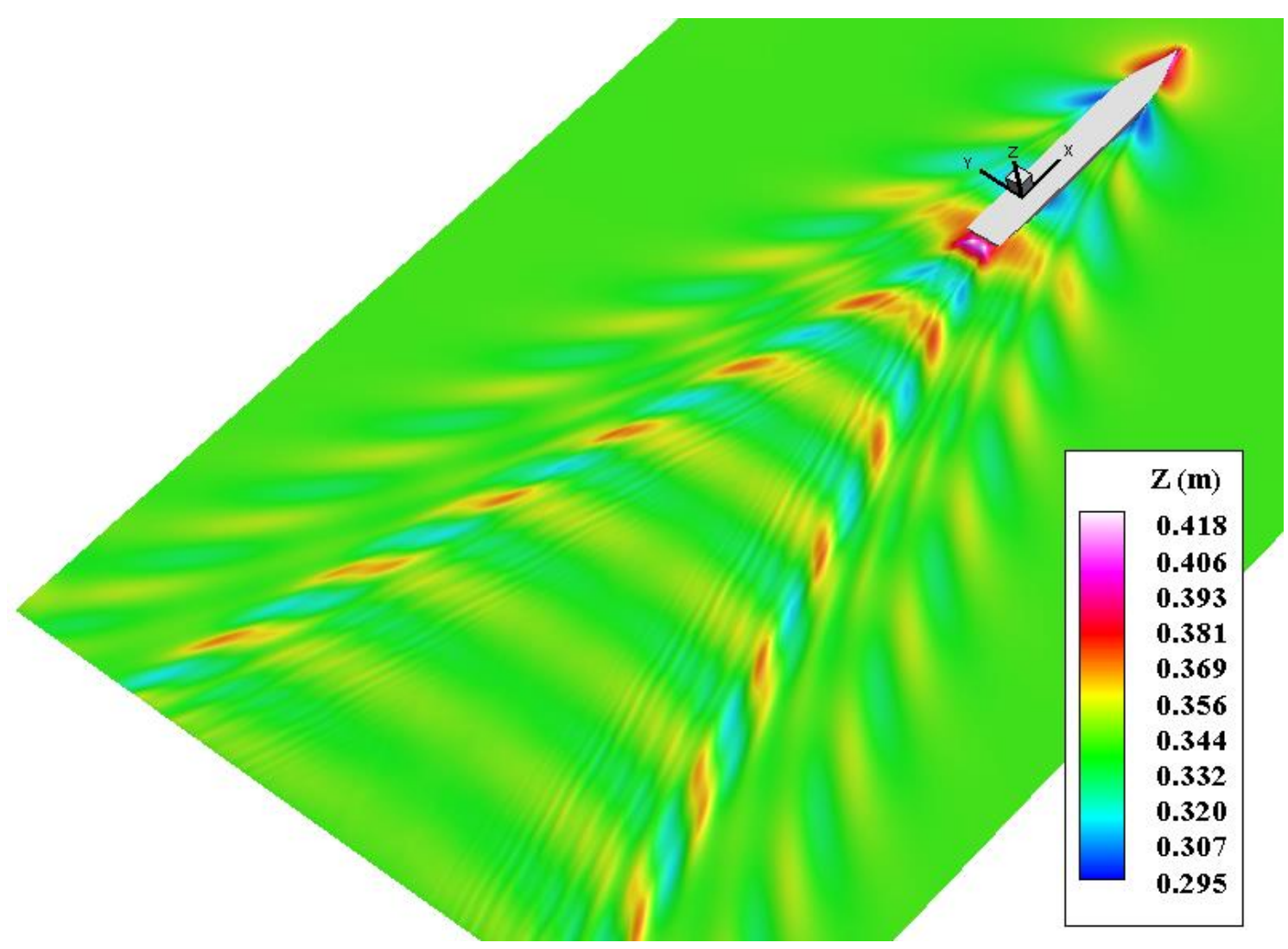

Fig. 7 Global wave pattern 


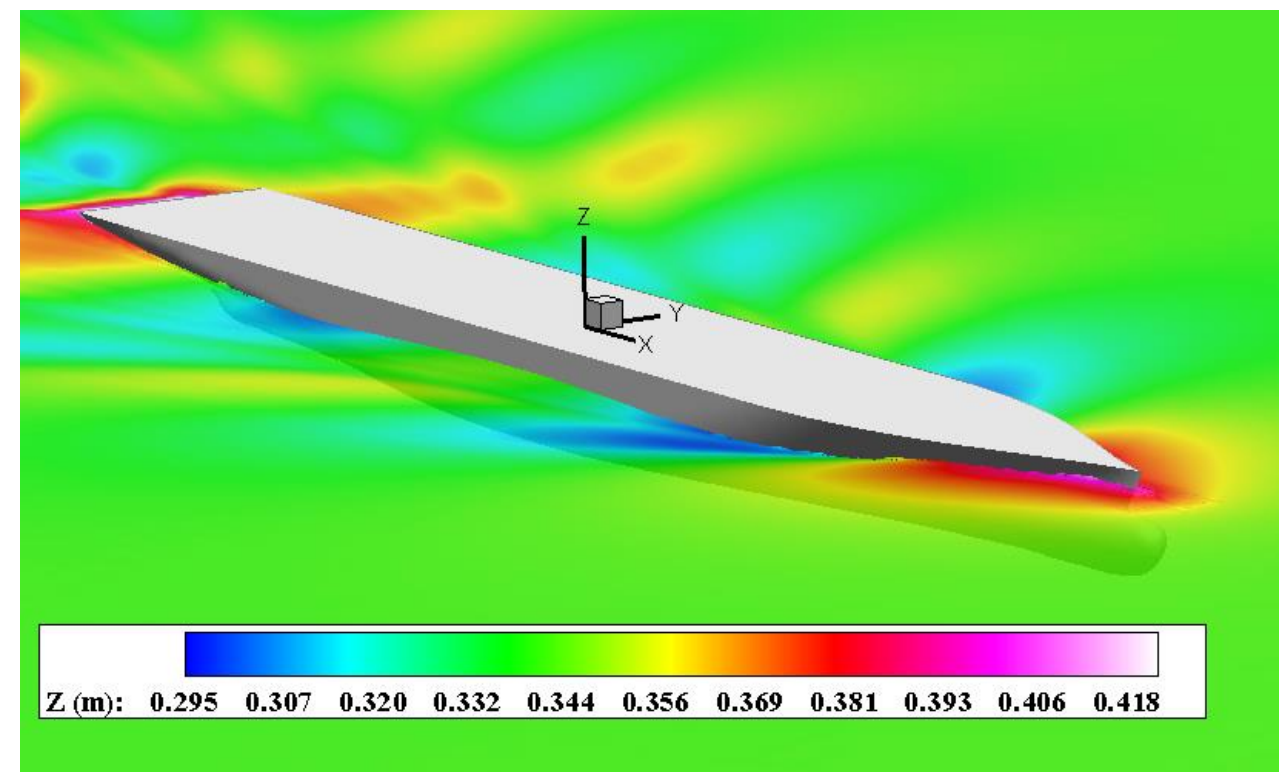

Fig. 8 Local wave pattern in bow region

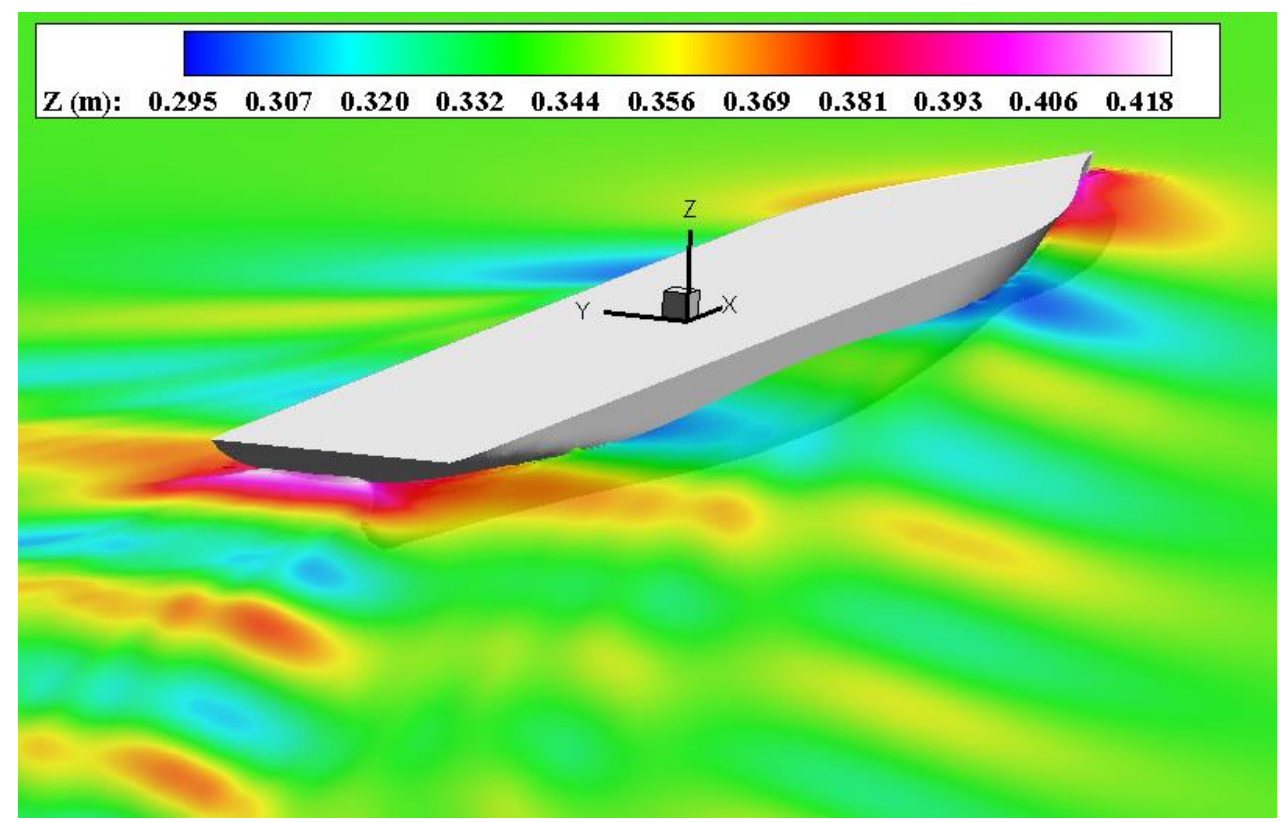

Fig. 9 Local wave pattern in stern region

RANSE approaches work well with near wall flows, but not that successful to predict the unsteady characteristics of separated flows [32]. In the flow around a ship scenario, there is a separation zone occurring behind the ship that creates a complicated turbulent flow field including large eddies. Inaccurate modeling of this zone causes the error to advance in flow direction, which results incorrect wave pattern calculations. By these reasons, the far field wave pattern calculation is open to possible mistakes. Figure10 shows the comparison of free-surface wave pattern with the experimental data [23]. In general, the estimation shows good agreement with experimental values with respect to both the magnitude and location of the Kelvin wave pattern. 
Yavuz Hakan Ozdemir, Taner Cosgun,

Ali Dogrul, Baris Barlas
A Numerical Application to Predict the Resistance and Wave Pattern of KRISO Container Ship

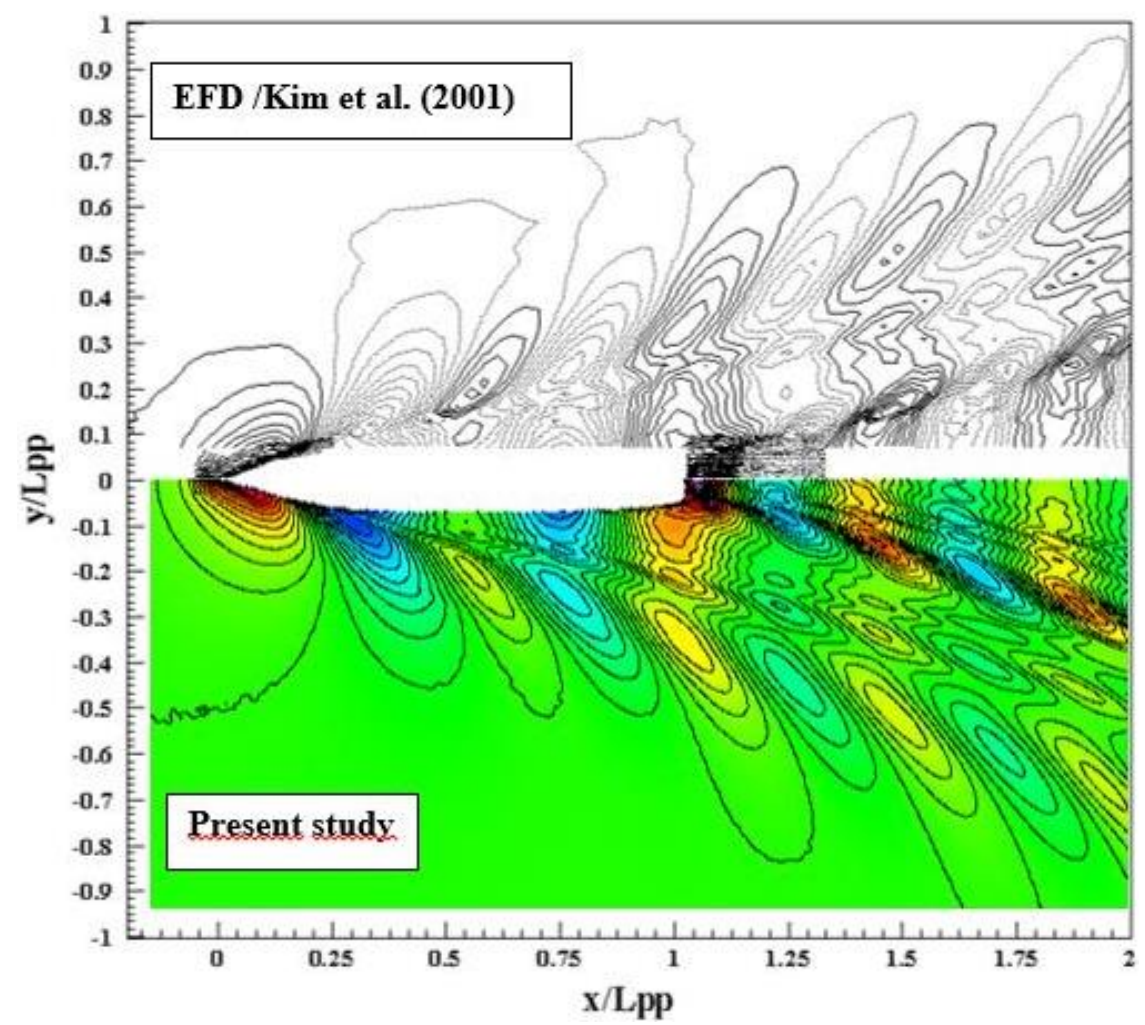

Fig. 10 Comparisons of wave pattern for EFD (top), CFD (bottom). Solid lines: positive values, dashed lines: negative values

Figure 11 shows how the free surface was represented in this CFD model by displaying the water volume fraction profile on the hull. In the figure, for instance, a value of 0.5 for the volume fraction of water implies that a computational cell is filled with $50 \%$ water and $50 \%$ air. This value therefore indicates the position of the water-air interface, which corresponds to the free surface.

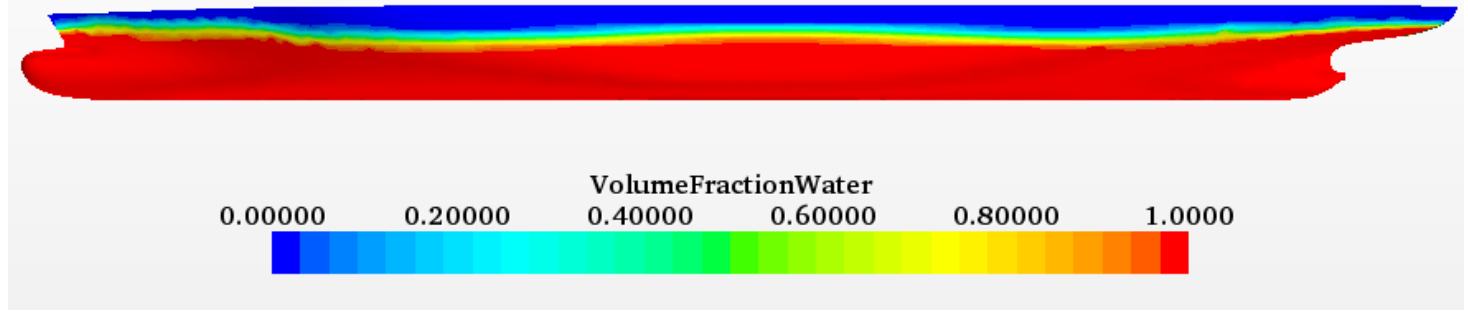

Fig. 11 Contours of volume of fraction (water) of KCS at $F n=0.26$

Figure 12 is the result of wave profile on the hull. The agreement with the experimental result is also very good. Some distinctions are seen at the bow and stern. Similar results were found by Banks et al. [31] in their CFD results. Their explanation for this discrepancy is that the experimental data was obtained through photo analysis Kim et al. [23] and therefore is subject to increased error compared to wave probe data. Also it is stated that the mesh structure in bow and stern region is insufficient in the study of Kim et al. [23]. They have gained better results by increasing the mesh number to 10 million. 


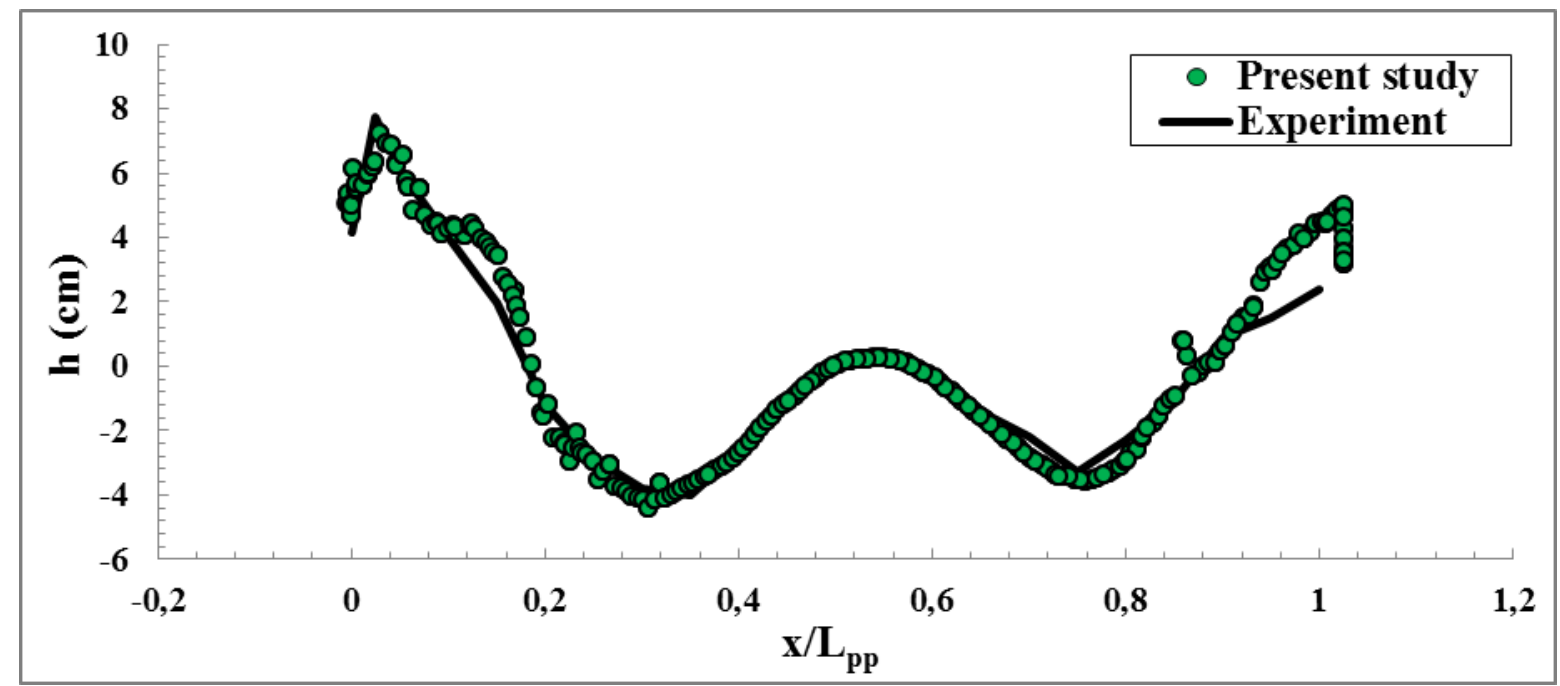

Fig. 12 Wave profile on the hull

Wave-cuts are obtained as the intersection of the wave pattern with different planes. Figure13 shows the wave-cuts obtained in different non-dimensional distances from centerline of the ship hull, which are of $0.0741,0.1509$ and 0.4224 , respectively. The results are close to the test data. And the far field wave profile is well simulated.

The comparison of axial velocity field on propeller plane between calculated and measured result are shown in Figure14. The right half of the figure is the measured result while the left half is the calculated result. The overall trend is satisfactory which means that the flow in the ship stern is also well captured although the flow is highly chaotic in that region.

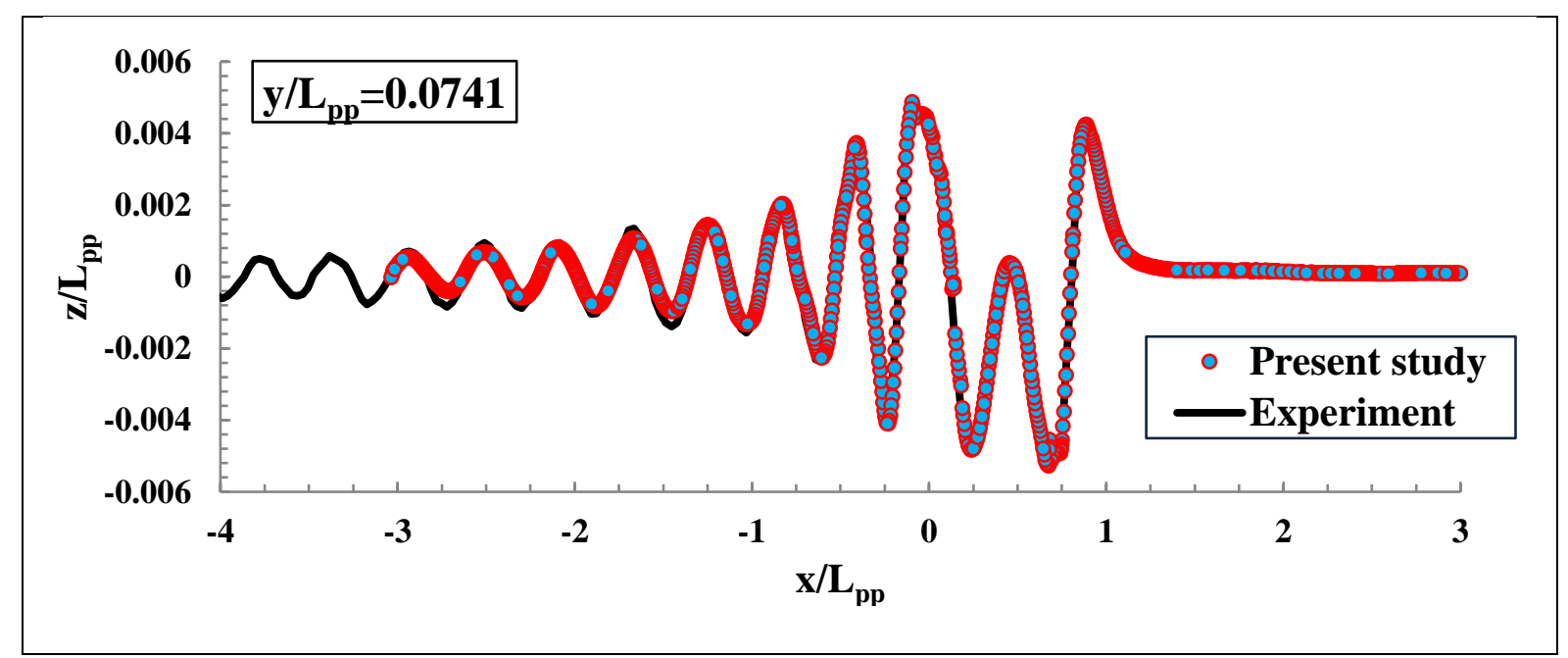


Yavuz Hakan Ozdemir, Taner Cosgun,

Ali Dogrul, Baris Barlas
A Numerical Application to Predict the Resistance and Wave Pattern of KRISO Container Ship

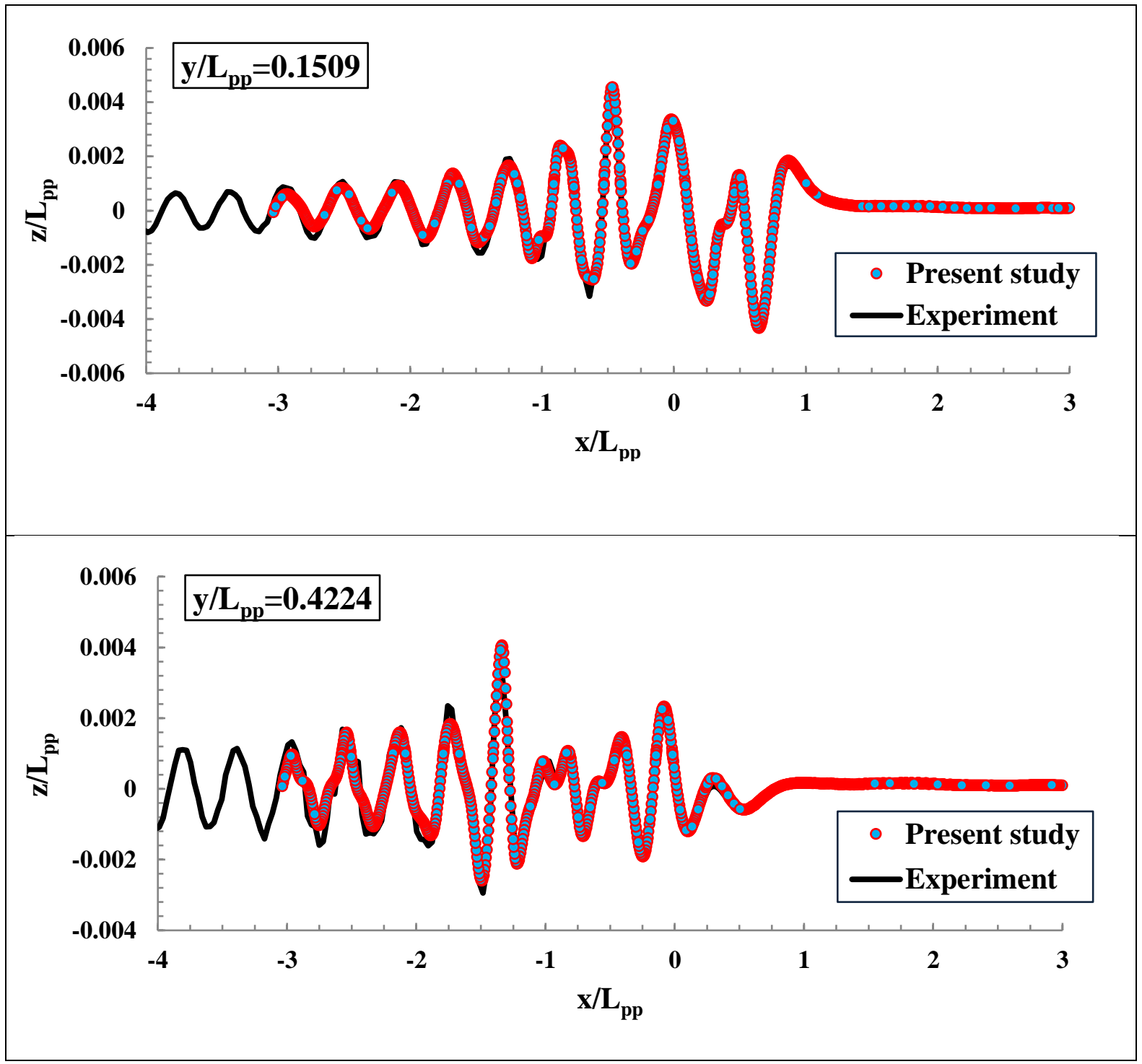

Fig. 13 Wave cut of free surface

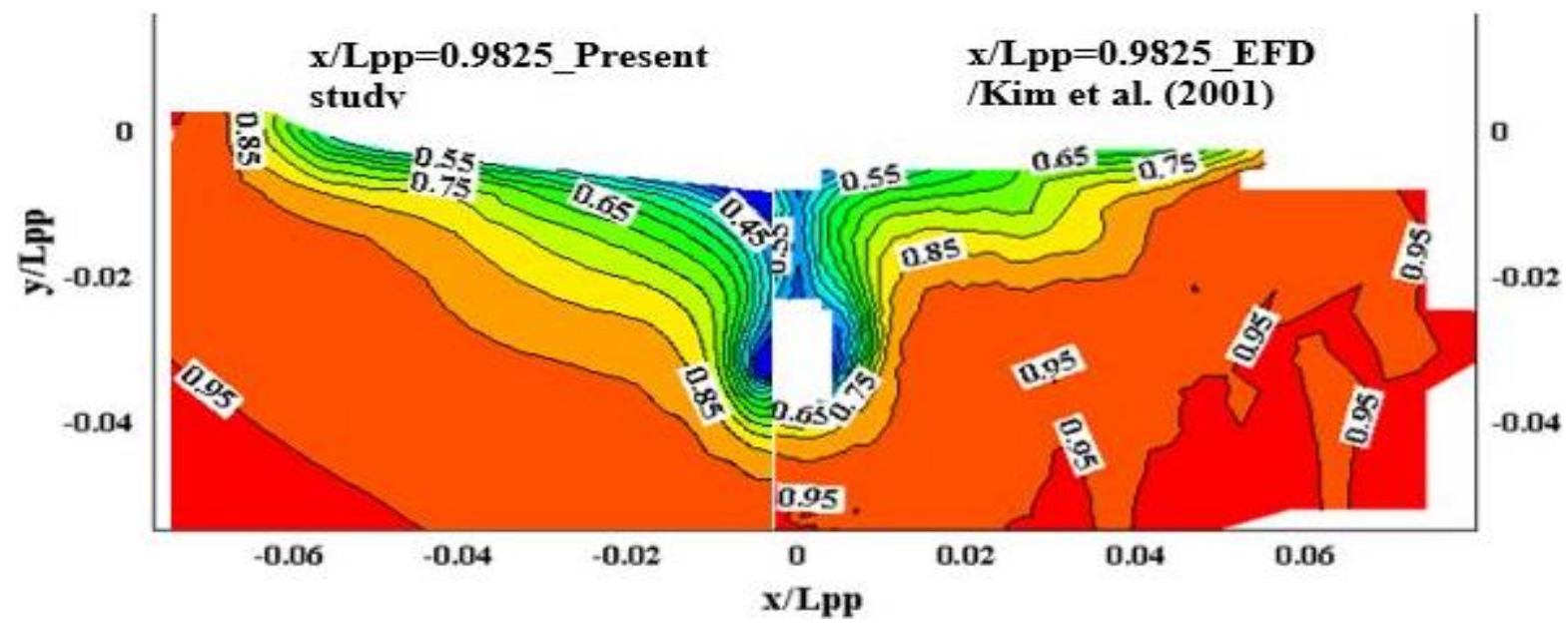

Fig. 14 Comparison of wake plane 
Figure 14 represents the nominal wake distribution related with the velocity field in the propeller disk area behind the stern. The nominal wake is crucial in propeller design. The nominal wake distribution can be implemented as a non-uniform velocity profile in propeller flow in order to determine the open water propeller performance characteristics taking the hull interaction into account. The general behavior of the wake distribution seems similar both for numerical and experimental results. Although, in some parts of the wake region the simulated wake is thicker than the experimental data, this is due to the fact that, the numerical result scan the whole propeller disk area while it is not possible to scan the whole propeller disk area in the experiment.

\section{Conclusions}

KCS container ship has a very complex hull shape. In this paper, development of a numerical tool based on RANS flow solver for an unstructured hexahedral mesh as the ship resistance simulation strategy is described. The main goal of this numerical study is: i) to show the capability of a general-purpose CFD code for design, analysis and feasibility of such a simulation for shipping industry ii) to model the far field wake pattern precisely. Numerical results have good concordance with the available experimental data. The algorithm and the software have good capabilities for simulation of such complex hydrodynamics problems. From the simulations of the KCS ship model, the following conclusions can be reached:

- A value of calculated total resistance coefficient for fine grid structure is satisfactory, with a margin of $2.77 \%$ to the experimental one.

- Obtained $C_{F}$ values are in good agreement with ITTC. The difference is about $1.49 \%$ for fine grid.

- Residual resistance coefficient $C_{R}$ is estimated with an error of $7.45 \%$ for fine grid. Magnitude of the error seems high because the residual resistance is low. The error in $C_{R}$ will increase while $C_{F}$ values come closer to the ITTC values.

- As can be seen from Table 5, the residual resistance is lower than the frictional resistance which means the ship has a well-designed hull shape.

- It can be seen from given wave cuts in Figure 10 that the wave deformations are modeled well. The far field wave is well predicted. In order to obtain far field wave pattern, large number of unstructured hexahedral mesh is used.

- In order to determine total ship resistance with CFD, large computation times are required with the current computer capability.

- The $k-\varepsilon$ turbulence model gives good results in fully turbulent free surface flows around ships.

- The given simulation is restricted to both single mesh structure and time step size. The effect of mesh structure and time step size will be investigated.

It may be concluded that the proposed method can evaluate both resistance and wave field with sufficient accuracy and can be used as a design tool for ship design. 
Yavuz Hakan Ozdemir, Taner Cosgun,

Ali Dogrul, Baris Barlas
A Numerical Application to Predict the Resistance and Wave Pattern of KRISO Container Ship

\section{REFERENCES}

[1] KOUH J.S., CHEN Y.J. and CHAU S.W.: Numerical study on scale effect of form factor. Ocean Engineering, 2009, 36: 403-413. http://dx.doi.org/10.1016/j.oceaneng.2009.01.011.

[2] PARK D.W, CHUN H.H.: Design practice for the stern hull form of a twin-skeg ship. Journal of Marine Science and Technology, 2009, 14 (3): 10-321. http://dx.doi.org/10.1007/s00773-009-0046-5.

[3] ATLAR M., KWANGCHEOL S., RODERICK S. and DANISMAN D.B.: Anti-slamming bulbous bow and tunnel stern applications on a novel Deep-V catamaran for improved performance. International Journal of Naval Architecture and Ocean Engineering, 2013, 5: 302-312. http://dx.doi.org/10.3744/JNAOE.2013.5.2.302.

[4] CHOI J.E., MIN K.S., KIM J.H., LEE S.B. and SEO H.W.: Resistance and propulsion characteristics of various commercial ships based on CFD results. Ocean Engineering, 2010, 37: 549-566. http://dx.doi.org/10.1016/j.oceaneng.2010.02.007.

[5] BETTLE M.C., GERBER A.G. and WATT G.D.: Unsteady analysis of the six DOF motion of a buoyantly rising submarine. Computers \& Fluids, $2009, \quad 38$ : $1833-1849$. http://dx.doi.org/10.1016/j.compfluid.2009.04.003.

[6] GUO B.J., DENG G.B. and STEEN S.: Verification and validation of numerical calculation of ship resistance and flow field of a large tanker. Ships and Offshore Structures, 2013, 8 (1) 3-14. http://dx.doi.org/10.1080/17445302.2012.669263.

[7] WANG B.L., GUO X.Y., LIU H and CHEN H.: Numerical simulations of wake signatures around highspeed ships. Journal of Hydrodynamics, 2014,26(6):986-989. http://dx.doi.org/10.1016/S10016058(14)60109-8.

[8] MAHMOOD S., HUANG D.: Computational Fluid Dynamics Based Bulbous Bow Optimization Using a Genetic Algorithm. Journal of Marine Science and Application, 2012, 11: 286-294. http://dx.doi.org/10.1007/s11804-012-1134-1.

[9] ZHA R.S., YE H.X., SHEN Z.R. and WAN D.C.: Numerical computations of resistance of high speed catamaran in calm water. Journal of Hydrodynamics,2014,26(6):930-938. http://dx.doi.org/10.1016/S1001$\underline{6058(14) 60102-5 .}$

[10] SU Y.M, WANG S., SHEN H.L. and DU X.: Numerical and experimental analyses of hydrodynamic performance of a channel type planning trimaran. Journal of Hydrodynamics, 2014,26(4):549-557. http://dx.doi.org/10.1016/S1001-6058(14)60062-7.

[11] STERN F., WANG Z., YANG J., SADAT-HOSSEINI H., MOUSAVIRAAD M., BHUSHAN S., DIEZ M., YOON S.H., WU P.C., YEON S.M.,DOGAN T, KIM D.H., VOLPI S, CONGER M, MICHAEL T, XING T,THODAL R.S. and GRENESTEDT J.L.: Recent progress in CFD for naval architecture and ocean engineering. Journal of Hydrodynamics, 2015, 27(1): 1-23. http://dx.doi.org/10.1016/S1001$\underline{6058(15) 60452-8 .}$

[12] JASAK H., VUKCEVIC V. and CHRIST D.: Rapid Free Surface simulation for Steady-State Hull Resistance with FVM using OpenFOAM. Proceedings 30th Symposium on Naval Hydrodynamics. Hobart, Tasmania, Australia, 2-7 November 2014.

[13] SEO J.H., SEOL D.M., LEE J.H and RHEE S.H.: Flexible CFD meshing strategy for prediction of ship resistance and propulsion performance. International Journal of Naval Architecture and Ocean Engineering, 2010, 2: 139-145. http://dx.doi.org/10.3744/JNAOE.2010.2.3.139.

[14] AHMED Y., SOARES C. G.: Simulation of free surface flow around a VLCC hull using viscous and potential flow methods. Ocean Engineering, 2009, 36: 691-696.

http://dx.doi.org/10.1016/j.oceaneng.2009.03.010.

[15] SRIDHAR D., BHANUPRAKASH T.V.K., and DAS H. N.: Frictional Resistance Calculations on a Ship using CFD. International Journal of Computer Applications, 2010, 11 (5): $24-31$. http://dx.doi.org/10.5120/1577-2109.

[16] KANDASAMY M., OOI S.K., CARRICA P., STERN F., CAMPANA E.F., PERI D., OSBORNE P., COTE J., MACDONALD N. and DE WAAL N.: CFD validation studies for a high-speed foil-assisted semi-planning catamaran. Journal of Marine Science and Technology, 2011, 16( 2): 157-167. http://dx.doi.org/10.1007/s00773-011-0120-7. 
A Numerical Application to Predict the Resistance and Wave Pattern of KRISO Container Ship
Yavuz Hakan Ozdemir, Taner Cosgun

Ali Dogrul, Baris Barlas

[17] PRANZITELLI A., DE NICOLA C. and MIRANDA S.: Steady state calculations of free surface flow around ship hulls and resistance prediction. Symposium on High Speed Marine Vehicles (HSMV) 2011. Italy.2011

[18] OZDEMIR Y.H., BARLAS B., YILMAZ T., and BAYRAKTAR S.: Numerical and experimental study of turbulent free surface flow for a fast ship model. Brodogradnja, 2014, 65 (1): 39-54

[19] PRAKASH M., SUBRAMANIAN V.: Simulation of Propeller - Hull Interaction Using Ranse Solver. The International Journal of Ocean and Climate Systems, 2010, 1 (3): 189-208. http://dx.doi.org/10.1260/17593131.1.3-4.189.

[20] CHAO K.Y.: Numerical propulsion simulation for the KCS container ship. Proceedings of CFD Workshop Tokyo 2005. Japan,2005

[21] LÜBKE L.O.: Numerical simulation of the flow around a propelled KCS container ship. Proceedings of CFD Workshop Tokyo 2005, Japan, 2005

[22] TEZDOGAN T., DEMIREL Y.K., KELLETT P., KHORASANCHI M., INCECIK A. and TURAN O.: Full-scale unsteady RANS CFD simulations of ship behavior and performance in head seas due to slow steaming. Ocean Engineering, 2015, 97: 186-206. http://dx.doi.org/10.1016/j.oceaneng.2015.01.011.

[23] KIM W.J., VAN D.H. and KIM D.H.: Measurement of flows around modern commercial ship models. Experiments in Fluids,2001, 31: 567-578. http://dx.doi.org/10.1007/s003480100332.

[24] PATANKAR S.V., SPALDING D.B.: A calculation procedure for heat, mass and momentum transfer in three-dimensional parabolic flows. International Journal of Heat and Mass Transfer, 1972, 15 (10): 17871806. http://dx.doi.org/10.1016/0017-9310(72)90054-3.

[25] International Towing Tank Conference (ITTC): Practical guidelines for ship CFD applications. Proceedings of the 26th International Towing Tank Conference, Brazil,2011

[26] ZHANG Z.R.: Verification and validation for RANS simulation of KCS container ship without/with propeller. Journal of Hydrodynamics, 2010, 22(5): 932-939. http://dx.doi.org/10.1016/S10016058(10)60055-8.

[27] UBBINK O.: Numerical prediction of two fluid systems with sharp interfaces Ph. D. Thesis. University of London. 1997

[28] MUZAFERIJ A, S., PERIC M.: Computation of free surface flows using interface-tracking and interfacecapturing methods. Chap.2 in Mahrenholtz, O. and Markiewicz, M. Nonlinear Water Wave Interaction. WIT Press, 1999

[29] BUCAN B., BUCA M.P. and RUZIC S.: Numerical Modeling of the flow around the Tanker Hull. Brodogradnja, 2008, 59 (2): 117-122

[30] Star CCM+ Documentation (version 6.06), User's Guide, CD-Adapco, 2011

[31] BANKS J., TURNOCK S.R., HUDSON D.A., BLAKE J.I.R. and PHILLIPS A.B.: Rans simulations of the multiphase flow around the KCS hull form. Proceedings Gothenburg 2010: A Workshop on CFD in Ship Hydrodynamics, Sweden, 2010

[32] BREUER M., JOVICIC N. and MAZAEV K.: Comparison of DES, RANS and LES for the separated Flow around a Flat plate at high incidence. International Journal for Numerical Methods in Fluids, 2003, 41:357388. http://dx.doi.org/10.1002/fld.445.

Submitted: $\quad$ 13.09.2015. Yavuz Hakan Ozdemir

Vocational School, Bartin University, Bartin, Turkey

Accepted: $\quad$ 16.03.2016. $\quad$ Taner Cosgun, tcosgun@yildiz.edu.tr

Ali Dogrul

Department of Naval Arch. and Marine Eng., Yildiz Technical University, Istanbul, Turkey.

Baris Barlas

Department of Naval Arch. and Marine Eng., Istanbul Technical University, Istanbul, Turkey 